\title{
Characterization of Seashell Waste through Calcination Process
}

\section{Karakterisasi Limbah Cangkang Kerang melalui Kalsinasi}

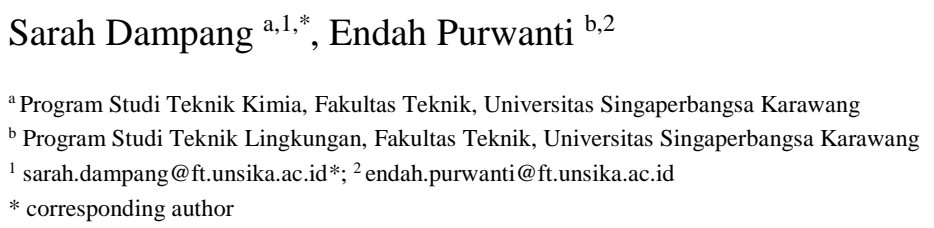

\section{ARTICLE INFO}

Article history

Received November 09, 2020

Revised December 14, 2020

Accepted January 31, 2021

\section{Keywords}

Calcination

Shells

Time

Temperature

Waste

\begin{abstract}
Seashell waste found in Tanjung Baru Beach, Karawang, which has not fully utilized. This waste can be widely used as an environmentally friendly material in various fields. Seashell waste is the source of $\mathrm{CaCO}_{3}$, and throughout the calcination process at the correct temperature, it can be converted to $\mathrm{CaO}$. The purpose of the calcination process is to obtain a solid $\mathrm{CaO}$ by releasing $\mathrm{CO}_{2}$ gas. The calcination process can carry out at temperatures of $800{ }^{\circ} \mathrm{C}, 900$ ${ }^{\circ} \mathrm{C}$, and $1000{ }^{\circ} \mathrm{C}$ with a calcination time of 2 hours, 3 hours, and 4 hours. The seashell waste is characterized and analyzed using the Fourier Transform Infrared Spectroscopy (FTIR), Scanning Electron Microscopy, and Energy Dispersive X-Ray (SEM-EDX). Before and after the calcination process, the FTIR spectrum of seashells is around $710 \mathrm{~cm}^{-1}-1476 \mathrm{~cm}^{-1}$, a characteristic peak of the C-O group from $\mathrm{CaCO}_{3}$. The spectrum of $3429 \mathrm{~cm}^{-1}-3468 \mathrm{~cm}^{-1}$ is a characteristic peak of the $\mathrm{O}-\mathrm{H}$ group from $\mathrm{Ca}(\mathrm{OH})_{2}$. The spectrum $2513.25 \mathrm{~cm}^{-1}$ is a characteristic peak of the $\mathrm{C}-\mathrm{H}$ group containing $\mathrm{CaO}$ appearing after calcination. The seashell powder is analyzed by using SEM-EDX with the result where the most dominant elements are $C(18.43 \%), O$ (52.07\%), and $\mathrm{Ca}(27.86 \%)$ from the calcined shells. The elements $C$, $\mathrm{Na}, \mathrm{Al}, \mathrm{Si}, \mathrm{Fe}$, and $\mathrm{Cu}$, are zero due to the heating process (calcination). The calcined seashell has also shown a rough surface and irregularly shaped particles.
\end{abstract}

This is an open access article under the CC-BY-SA license.

\section{Pendahuluan}

Pemanfaatan cangkang kerang sebagai sumber $\mathrm{CaO}$ dan bahan pengemban untuk katalis heterogen dapat mengurangi biaya produksi biodiesel dan dapat mengurangi keberadaan limbah cangkang kerang tersebut. Salah satu sumber $\mathrm{CaCO}_{3}$ yang mudah diperoleh adalah cangkang kerang yang mengandung $98 \% \mathrm{CaCO}_{3}, 0,79 \%$ berat $\mathrm{MgCO}_{3}$ dan $0,15 \% \mathrm{SrCO}_{3}$ [1, 2]. Cangkang kerang sebagian besar terdiri dari $\mathrm{CaCO}_{3}\left(95-99 \% \mathrm{CaCO}_{3}\right)$ tetapi ketika dipanaskan hingga suhu tertentu menyebabkan pembentukan oksida logam $\mathrm{CaO}$ tunggal [3]. Adanya kandungan $\mathrm{Ca}$ yang tinggi pada limbah cangkang kerang sehingga limbah cangkang kerang dapat digunakan sebagai sumber penyerap $\mathrm{CO}_{2}$ [4]. Limbah kerang dapat juga diubah menjadi mineral baru untuk bahan semen yang berkelanjutan, dimana digunakan sebagai pengganti dan pengisi mineral tambahan pada semen [5]. Disamping itu limbah cangkang kerang dapat digunakan sebagai bahan pendukung untuk proses sintesis fotokatalisis [6]. Penggunaan limbah cangkang kerang sebagai reagen yang efektif yang dapat menghilangkan fosfor dari air limbah [7]. Ketika dipanaskan pada suhu yang lebih tinggi dari 750-800 ${ }^{\circ} \mathrm{C}$ cangkang kerang dapat berubah menjadi kalsium oksida. $\mathrm{CaO}$ dapat dihasilkan dari dekomposisi $\mathrm{CaCO}_{3}$ atau $\mathrm{Ca}(\mathrm{OH})_{2}$. Katalis $\mathrm{CaO}$ dapat dibuat melalui proses kalsinasi $\mathrm{CaCO}_{3}$. 
Proses kalsinasi kerang bertujuan untuk menghilangkan kandungan air, senyawa organik, serta karbon dioksida yang terdapat di dalam cangkang kerang. Oleh karena itu, untuk mendapatkan katalis $\mathrm{CaO}$ yang baik dari cangkang kerang suhu kalsinasi yang digunakan harus di atas $800{ }^{\circ} \mathrm{C}$ dengan waktu 2-4 jam [8]. Penelitian sebelumnya menunjukan bahwa terjadi peningkatan luas permukaan $\mathrm{CaO}$ dan meningkatkan aktivitas katalitik yang dikalsinasi pada $900{ }^{\circ} \mathrm{C}$ selama 4 jam memiliki kekuatan sebagai energi aktivasi desorpsi $\mathrm{CO}_{2}$ sekitar 22\%-45\% [9]. Penelitian terkait menyimpulkan bahwa pada kalsinasi $1000{ }^{\circ} \mathrm{C}$ selama 3 jam, cangkang kerang dapat digunakan kembali dalam produksi biodiesel sebagai katalis [10]. Penelitian yang lain menemukan bahwa suhu optimasi kalsinasi pada suhu $1000{ }^{\circ} \mathrm{C}$ selama 3 jam, aktivasi katalitik cangkang kerang meningkat sebagai katalis dalam produksi biodiesel [1]. Cangkang kerang dikalsinasi pada suhu $900{ }^{\circ} \mathrm{C}$ selama 2 jam menunjukkan aktivitas tertinggi dengan peningkatan luas permukaan dengan morfologi yang lebih baik [11]. Limbah cangkang kerang ditemukan sebagai sumber kalsium karbonat $\left(\mathrm{CaCO}_{3}\right)$ terkaya dan dengan treatment yang tepat telah digunakan untuk berbagai keperluan dalam kehidupan sehari-hari. Ketika dikalsinasi pada suhu yang tepat $\mathrm{CaCO}_{3}$ dikonversi menjadi $\mathrm{CaO}$, yang merupakan oksida logam. $\mathrm{CaO}$ yang berasal dari cangkang limbah dapat digunakan sebagai katalis dalam proses produksi biodiesel. Pemanfaatan kerang limbah sebagai sumber $\mathrm{CaO}$ tidak hanya digunakan sebagai katalis tetapi juga menambah nilai limbah yang dihasilkannya [12,13]. Cangkang kerang sangat melimpah di Pantai Tanjung Baru Karawang dan belum dimanfaatkan secara maksimal sebagai sumber kalsium karbonat $\left(\mathrm{CaCO}_{3}\right)$. Tujuan dari penelitian ini memanfaatkan cangkang kerang sebagai sumber kalsium karbonat dengan variasi waktu dan suhu kalsinasi kemudian dilakukan uji karakterisasi. Dan diharapkan $\mathrm{CaO}$ yang diperoleh dapat diaplikasikan sebagai material yang ramah lingkungan dan penggunaannya secara luas di berbagai bidang.

\section{Metodologi Penelitian}

\subsection{Bahan}

Limbah cangkang kerang diambil di Pantai Tanjung Baru Karawang kira-kira $38 \mathrm{~km}$ dari Universitas Singaperbangsa Karawang. Adapun bahan yang lain adalah larutan $\mathrm{NaOH} 10 \%$ dan Aquades.

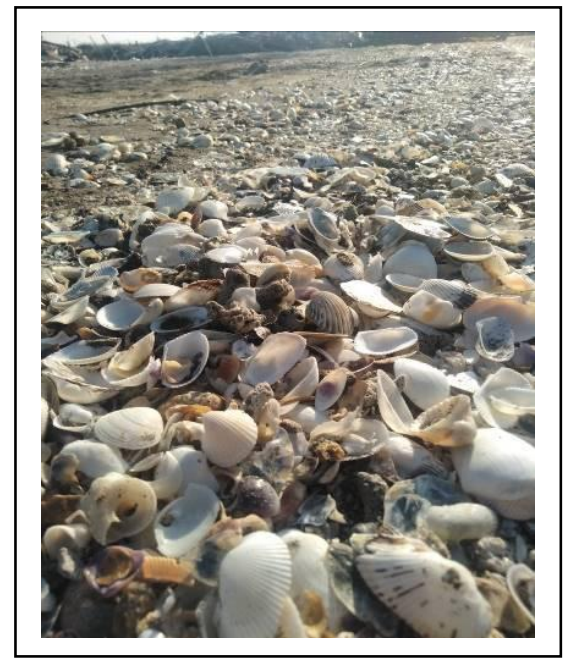

Gambar 1. Limbah Cangkang Kerang Laut

\subsection{Prosedur}

Cangkang kerang terlebih dahulu dipilah-pilih yang bentuknya masih utuh dan berukuran besar kemudian dibersihkan dengan menggunakan air bersih kemudian dijemur di bawah sinar matahari. Cangkang kerang kemudian dibersihkan lagi dengan menggunakan $\mathrm{NaOH} 10 \%$ dan aquades untuk menghilangkan kotoran-kotoran yang masih menempel pada cangkang kerang [9]. Cangkang yang telah bersih kemudian dijemur lagi di bawah sinar matahari sampai kering. Cangkang kerang yang sudah kering digiling dan dihaluskan untuk mendapatkan serbuk dan dikeringkan kembali di oven selama 24 jam pada suhu $105{ }^{\circ} \mathrm{C}$ [14]. Sampel yang telah dioven itu diayak dengan ukuran 100-10 mesh untuk menyeragamkan ukuran sampel. Proses kalsinasi dilakukan dengan cara sampel ditimbang masing-masing 1 gr disimpan di desikator kemudian dikalsinasi di dalam furnace listrik 
merk Ney Fulcan dengan variasi suhu $800{ }^{\circ} \mathrm{C}$ dengan rentang waktu 2-4 jam [8]; suhu $900{ }^{\circ} \mathrm{C}$ dengan rentang waktu 2-4 jam [5]; dan $1000^{\circ} \mathrm{C}$ dengan rentang waktu 2-4 jam [1]. Adapun tujuan dari proses kalsinasi ini adalah untuk mendapatkan padatan $\mathrm{CaO}$ dengan membebaskan gas $\mathrm{CO}_{2}$ berdasarkan persamaan reaksi di bawah ini [15]

$\mathrm{CaCO}_{3}(\mathrm{~s}) \longrightarrow \mathrm{CaO}(\mathrm{s})+\mathrm{CO}_{2}(\mathrm{~g}) \Delta \mathrm{H}=182,1 \mathrm{~kJ} \mathrm{~mol}^{-1}$

Sampel selanjutnya dikarakterisasi dan dianalisis berdasarkan analisis gugus fungsi menggunakan Fourier Transform Infrared Spectroscopy (FTIR) merk Prestige 21, Shimadzu dan analisis topografi, morfologi, dan komposisi menggunakan Scanning Electron Microscopy (SEM) merk JEOL JSM IT300LV.

\section{Hasil dan Pembahasan}

\subsection{Karakterisasi FTIR}

Berdasarkan Gambar 2, 3, dan 4 dapat dilihat spektrum IR serbuk cangkang kerang yang sebelum dikalsinasi dan sesudah dikalsinasi. Berdasarkan spektrum IR tersebut muncul beberapa puncak yang berbeda. Ada puncak yang tidak muncul pada serapan serbuk cangkang kerang sebelum kalsinasi tetapi muncul pada spektrum setelah kalsinasi. Pada gambar tersebut sebelum kalsinasi muncul pita serapan pada bilangan gelombang $3429,43 \mathrm{~cm}^{-1}$ dan setelah kalsinasi juga muncul beberapa bilangan gelombang sekitar $3400 \mathrm{~cm}^{-1}$ yang merupakan pita serapan vibrasi gugus $\mathrm{O}-\mathrm{H}$ dari $\mathrm{Ca}(\mathrm{OH})_{2}$ disebabkan oleh dasar pembentukan kelompok gugus $\mathrm{O}-\mathrm{H}$ yang melekat di atom kalsium [16]. Pada Spektrum IR tersebut juga dapat dilihat perubahan pita serapan pada bilangan gelombang 1475,54 $\mathrm{cm}^{-1}$ dimana pada daerah tersebut pada serbuk cangkang kerang sebelum kalsinasi muncul puncak yang tajam sedangkan setelah kalsinasi puncaknya melebar. Pada bilangan gelombang tersebut merupakan vibrasi $\mathrm{C}-\mathrm{O}$ pada gugus fungsi karbonat dari $\mathrm{CaCO}_{3}$. Pita serapan pada serbuk cangkang kerang setelah kalsinasi pada beberapa variasi waktu secara umum pola serapan tidak jauh berbeda walaupun terdapat perbedaan pada intensitas serapan. Akan tetapi variasi suhu cukup mempengaruhi hasil spektrum IR yaitu ditunjukkan dengan semakin melebarnya puncak spektrum seiring dengan bertambahnya suhu kalsinasi. Hal ini mengindikasikan bahwa telah berubahnya $\mathrm{CaCO}_{3}$ menjadi $\mathrm{CaO}$ akibat proses pemanasan. Selain itu munculnya $\mathrm{CaO}$ dapat dilihat dari adanya pita serapan pada panjang gelombang $2513,25 \mathrm{~cm}^{-1}$ yang merupakan karakteristik puncak gugus fungsi $\mathrm{C}-\mathrm{H}$. Sampel yang mengandung $\mathrm{CaO}$ dapat tampak dalam vibrasi $\mathrm{C}-\mathrm{H}$ stretching. Keberadaan $\mathrm{CaO}$ juga dapat dilihat dari munculnya pita serapan pada panjang gelombang $709,80 \mathrm{~cm}^{-1}$ merupakan finger print yang menunjukkan adanya ikatan $\mathrm{CaO}$ [17].

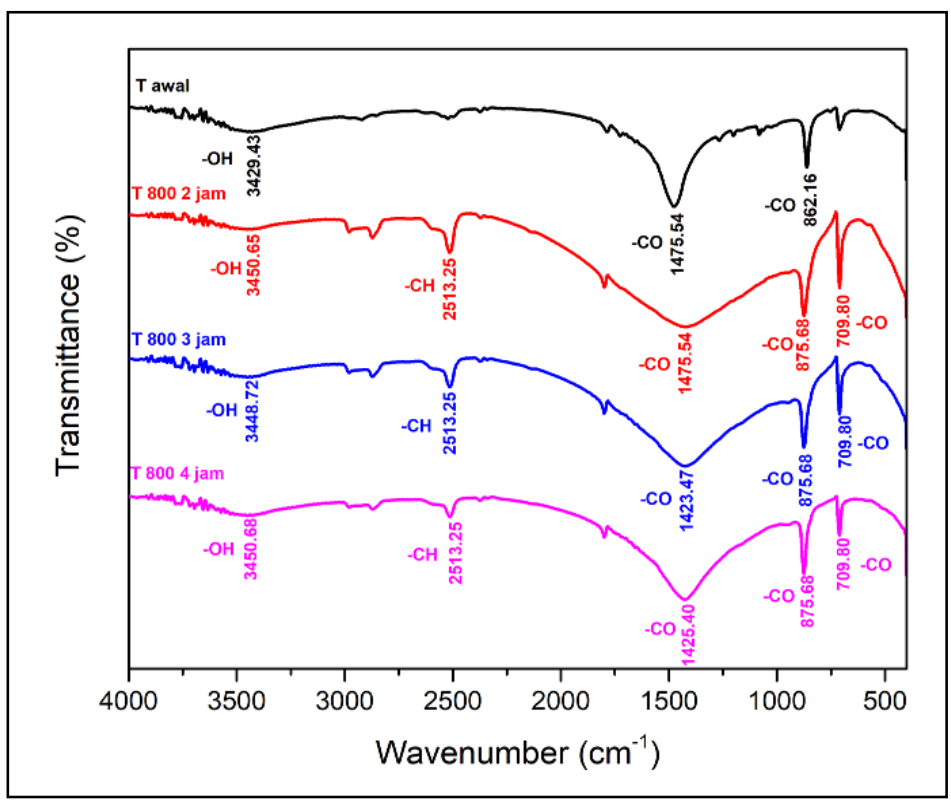

Gambar 2. FTIR sebelum dan sesudah kalsinasi $\left(800^{\circ} \mathrm{C}\right)$ 


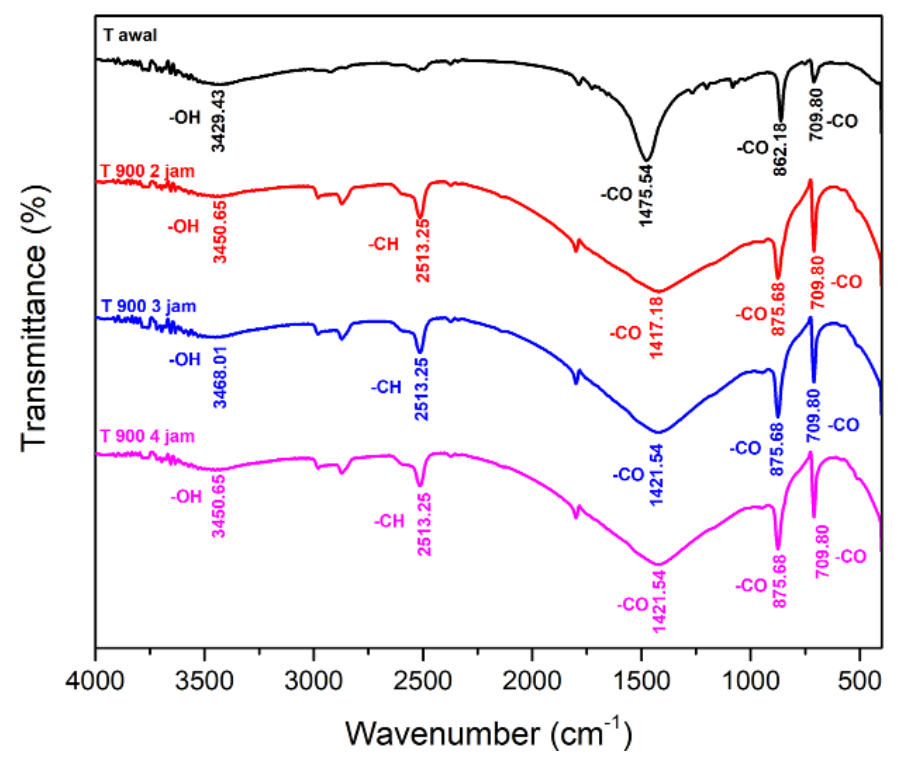

Gambar 3. FTIR sebelum dan sesudah kalsinasi $\left(900^{\circ} \mathrm{C}\right)$

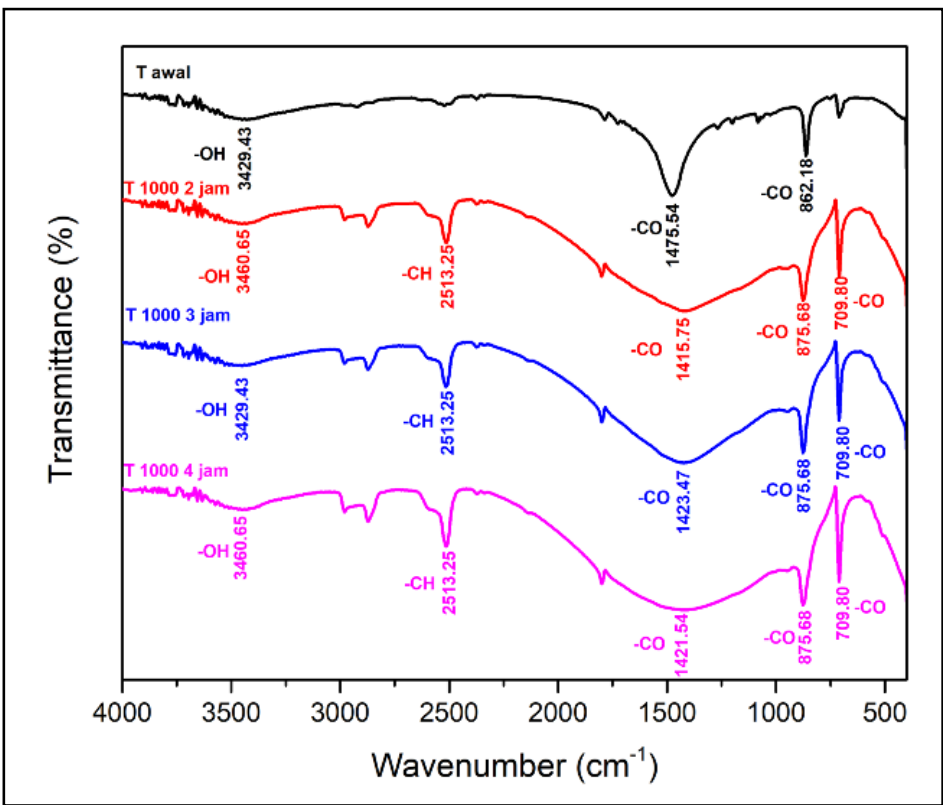

Gambar 4. FTIR sebelum dan sesudah kalsinasi $\left(1000^{\circ} \mathrm{C}\right)$

\subsection{Karakterisasi SEM-EDX}

Serbuk cangkang kerang dianalisis menggunakan EDX dengan hasil yang diperoleh bahwa elemen yang paling mendominasi adalah $\mathrm{C}(18,43 \%), \mathrm{O}(52,07 \%)$, dan $\mathrm{Ca}(27,86 \%)$ seperti pada Tabel 1. Pada penelitian ini ditemukan bahwa cangkang kerang yang telah dikalsinasi, elemen $\mathrm{C}$, $\mathrm{Na}, \mathrm{Al}, \mathrm{Si}, \mathrm{Fe}$, dan $\mathrm{Cu}$ hasilnya nihil disebabkan adanya proses pemanasan (kalsinasi). Sedangkan untuk elemen $\mathrm{Ca}$ dan $\mathrm{O}$ pada cangkang kerang yang dikalsinasi pada $800{ }^{\circ} \mathrm{C}$ komposisi $\mathrm{O}(56,97 \%)$ dan $\mathrm{Ca}(43,03 \%)$ pada Gambar 5, suhu $900{ }^{\circ} \mathrm{C}$ komposisi $\mathrm{O}(62,71 \%)$ dan $\mathrm{Ca}(37,29 \%)$ pada Gambar 6 dan suhu $1000^{\circ} \mathrm{C}$ kandungan $\mathrm{O}(63,56 \%)$ dan $\mathrm{Ca}(36,44 \%)$ pada Gambar 7 . Hasil yang diperoleh lebih rendah dibanding penelitian sebelumnya [16] dengan kandungan $\mathrm{O}(50,14 \%)$ dan $\mathrm{C}$ $(49,86)$ lebih tinggi. Hal ini disebabkan pengambilan sampel cangkang kerang di tempat yang berbeda. Pada pengujian SEM, cangkang kerang yang dikalsinasi memperlihatkan permukaan yang kasar dan partikel berbentuk tidak teratur yang berkumpul menjadi bulk dengan diameter individu 1 $\mu \mathrm{m}$. 
Tabel 1. Komposisi Cangkang Kerang Sebelum Kalsinasi

\begin{tabular}{ccc}
\hline Elemen & Weight \% & Atomic \% \\
\hline $\mathrm{C}$ & 18,43 & 27,71 \\
$\mathrm{O}$ & 52,07 & 58,77 \\
$\mathrm{Na}$ & 0,41 & 0,32 \\
$\mathrm{Al}$ & 0,39 & 0,26 \\
$\mathrm{Si}$ & 0,38 & 0,24 \\
$\mathrm{Ca}$ & 27,86 & 12,56 \\
$\mathrm{Fe}$ & 0,20 & 0,06 \\
$\mathrm{Cu}$ & 0,27 & 0,08 \\
\hline Total & 100,00 & 100,00 \\
\hline
\end{tabular}
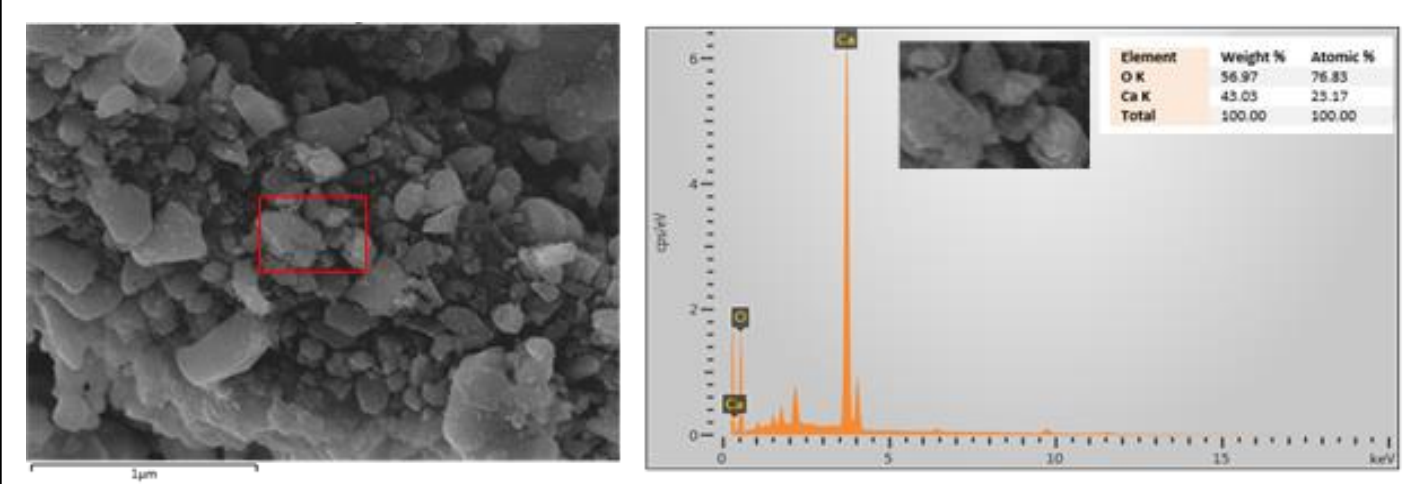

Gambar 5. SEM-EDX sebelum dan sesudah kalsinasi $\left(800{ }^{\circ} \mathrm{C}\right)$
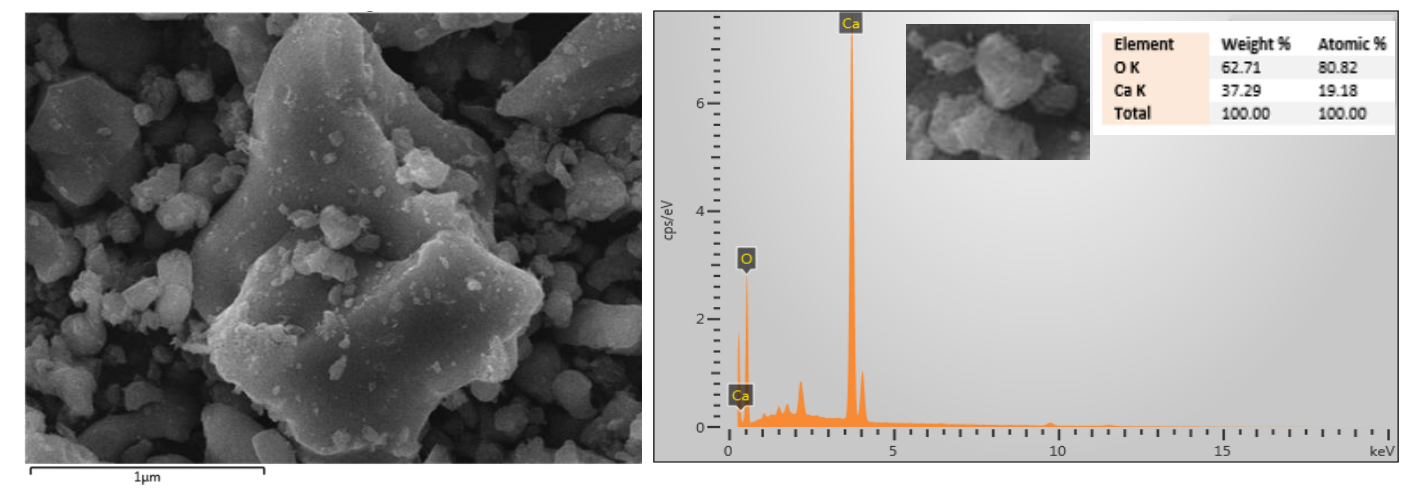

Gambar 6. SEM-EDX sebelum dan sesudah kalsinasi $\left(900{ }^{\circ} \mathrm{C}\right)$
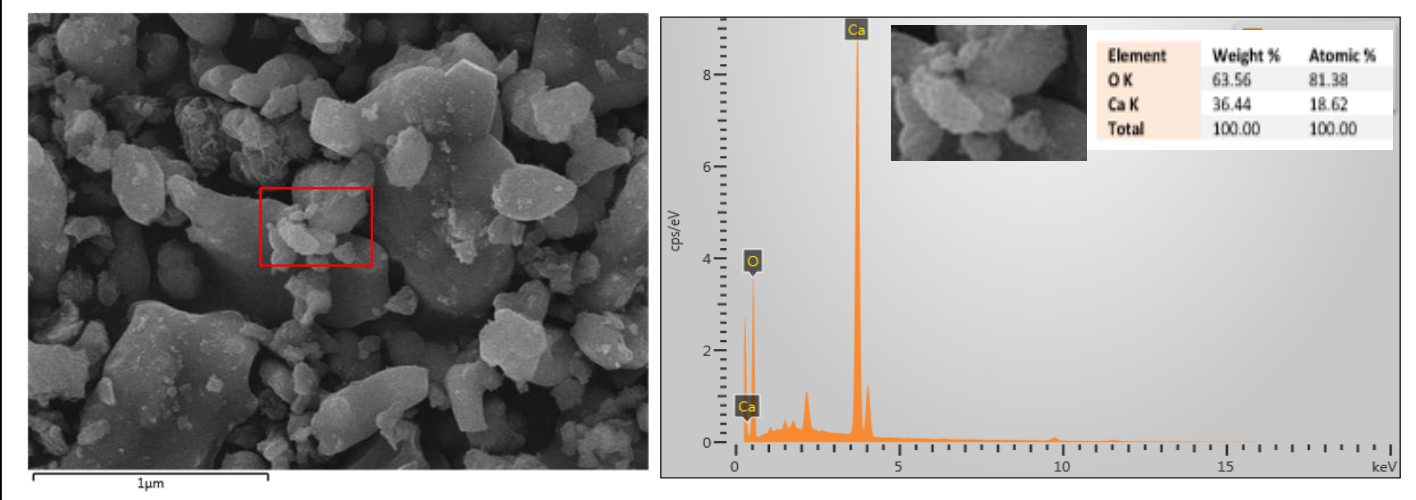

Gambar 7. SEM-EDX sebelum dan sesudah kalsinasi $\left(1000^{\circ} \mathrm{C}\right)$ 


\section{Kesimpulan}

Analisis FTIR pada proses kalsinasi dengan variasi waktu 2, 3, dan 4 jam dan variasi suhu 800 ${ }^{\circ} \mathrm{C}, 900{ }^{\circ} \mathrm{C}$, dan $1000{ }^{\circ} \mathrm{C}$ mengasilkan daerah spektrum yang sama yakni $2513,25 \mathrm{~cm}^{-1}$ yang merupakan karakteristik puncak gugus $\mathrm{C}-\mathrm{H}$ yang mengandung Kalsium Oksida. Dan keberadaan $\mathrm{CaO}$ juga dapat dilihat dari munculnya pita serapan pada panjang gelombang $709,80 \mathrm{~cm}^{-1}$ merupakan finger print yang menunjukkan adanya ikatan $\mathrm{CaO}$. Secara umum setelah kalsinasi pada beberapa variasi waktu 2,3 , dan 4 jam, pola serapan tidak jauh berbeda walaupun terdapat perbedaan pada intensitas serapan. Pada analisis SEM-EDX, semakin tinggi suhu kalsinasi kandungan Kalsium semakin rendah akan tetapi gambar permukaan cangkang kerang memiliki gambar permukaan yang sama yaitu berbentuk partikel tidak beraturan.

\section{Ucapan Terima Kasih}

Penulis mengucapkan terima kasih kepada Kementerian Riset dan Teknologi/Badan Riset dan Inovasi Nasional melalui program Hibah Penelitian Dosen Pemula yang telah mendanai keseluruhan proses penelitian ini. Dan penulis juga mengucapkan terima kasih kepada semua pihak yang terlibat hingga terlaksananya penelitian ini.

\section{Daftar Pustaka}

[1] Sirisomboonchai, S., Abuduwayiti, M., Guan, G., Samart, C., Abliz, S., Hao, X., Kusakabe, K. and Abudula, A., "Biodiesel production from waste cooking oil using calcined scallop shell as catalyst," Energy Convers. Manag., vol. 95, pp. 242-247, 2015, doi: 10.1016/j.enconman.2015.02.044.

[2] G. L. Yoon, B. T. Kim, B. O. Kim, and S. H. Han, "Chemical-mechanical characteristics of crushed oyster-shell," Waste Manag., vol. 23, no. 9, pp. 825-834, 2003, doi: 10.1016/S0956-053X(02)00159-9.

[3] D. L. Kaplan, "Mollusc shell structures: Novel design strategies for synthetic materials," Curr. Opin. Solid State Mater. Sci., vol. 3, no. 3, pp. 232-236, 1998, doi: 10.1016/S1359-0286(98)80096-X.

[4] Y. F. Huang, Y. T. Lee, P. Te Chiueh, and S. L. Lo, "Microwave calcination of waste oyster shells for CO 2 capture," Energy Procedia, vol. 152, pp. 1242-1247, 2018, doi: 10.1016/j.egypro.2018.09.176.

[5] J. Wang, E. Liu, and L. Li, "Characterization on the recycling of waste seashells with Portland cement towards sustainable cementitious materials," J. Clean. Prod., vol. 220, pp. 235-252, 2019, doi: 10.1016/j.jclepro.2019.02.122.

[6] Wang, W., Lin, F., Yan, B., Cheng, Z., Chen, G., Kuang, M., Yang, C. and Hou, L., "The role of seashell wastes in TiO2/Seashell composites: Photocatalytic degradation of methylene blue dye under sunlight," Environ. Res., vol. 188, no. March, p. 109831, 2020, doi: 10.1016/j.envres.2020.109831.

[7] H. B. Kwon, C. W. Lee, B. S. Jun, J. Do Yun, S. Y. Weon, and B. Koopman, "Recycling waste oyster shells for eutrophication control," Resour. Conserv. Recycl., vol. 41, no. 1, pp. 75-82, 2004, doi: 10.1016/j.resconrec.2003.08.005.

[8] M. Kouzu and J. S. Hidaka, "Transesterification of vegetable oil into biodiesel catalyzed by CaO: A review," Fuel, vol. 93, pp. 1-12, 2012, doi: 10.1016/j.fuel.2011.09.015.

[9] R. Risso, P. Ferraz, S. Meireles, I. Fonseca, and J. Vital, "Highly active Cao catalysts from waste shells of egg, oyster and clam for biodiesel production," Appl. Catal. A Gen., vol. 567, no. August, pp. 56-64, 2018, doi: 10.1016/j.apcata.2018.09.003.

[10]N. Nakatani, H. Takamori, K. Takeda, and H. Sakugawa, "Transesterification of soybean oil using combusted oyster shell waste as a catalyst," Bioresour. Technol., vol. 100, no. 3, pp. 1510-1513, 2009, doi: 10.1016/j.biortech.2008.09.007.

[11] P. L. Boey, G. P. Maniam, S. A. Hamid, and D. M. H. Ali, "Utilization of waste cockle shell (Anadara granosa) in biodiesel production from palm olein: Optimization using response surface methodology," Fuel, vol. 90, no. 7, pp. 2353-2358, 2011, doi: 10.1016/j.fuel.2011.03.002.

[12]J. Boro, D. Deka, and A. J. Thakur, "A review on solid oxide derived from waste shells as catalyst for biodiesel production," Renew. Sustain. Energy Rev., vol. 16, no. 1, pp. 904-910, 2012, doi: 10.1016/j.rser.2011.09.011. 
[13] Y. Y. Su, H. H. Huang, T. H. Yu, C. C. Tseng, H. J. Tsai, and W. K. Hsu, "Optical property of nature source: UV-visible emissions from calcined oyster shells," Opt. Mater. (Amst)., vol. 101, no. February, p. 109736, 2020, doi: 10.1016/j.optmat.2020.109736.

[14] S. Kaewdaeng, P. Sintuya, and R. Nirunsin, "Biodiesel production using calcium oxide from river snail shell ash as catalyst," Energy Procedia, vol. 138, pp. 937-942, 2017, doi: 10.1016/j.egypro.2017.10.057.

[15]B. R. Stanmore and P. Gilot, "Review-calcination and carbonation of limestone during thermal cycling for CO2 sequestration," Fuel Process. Technol., vol. 86, no. 16, pp. 1707-1743, 2005, doi: 10.1016/j.fuproc.2005.01.023.

[16] W. Suryaputra, I. Winata, N. Indraswati, and S. Ismadji, "Waste capiz (Amusium cristatum) shell as a new heterogeneous catalyst for biodiesel production," Renew. Energy, vol. 50, pp. 795-799, 2013, doi: 10.1016/j.renene.2012.08.060.

[17]P. Raizada, P. Shandilya, P. Singh, and P. Thakur, " Solar light-facilitated oxytetracycline removal from the aqueous phase utilizing a $\mathrm{H} 2 \mathrm{O} 2$ /ZnWO 4 /CaO catalytic system ," J. Taibah Univ. Sci., vol. 11, no. 5, pp. 689-699, 2017, doi: 10.1016/j.jtusci.2016.06.004. 